\title{
Physicochemical Characterization of Local clay from El-Oued Region, Southeastern of Algeria
}

Djamel Atia ${ }^{a}$, Ammar Zobeidi*,b, Abasse Kamarchou ${ }^{b}$, Salem Atia ${ }^{b}$

(a) Echahid Hamma Lakhdar, El-Oued University. 39000 - Algeria

(b) Pollution and waste treatment laboratory (PWTL), Kasdi Merbah Ouargla University .P.O. Box 511, 30000, Algeria.

Graphical abstract

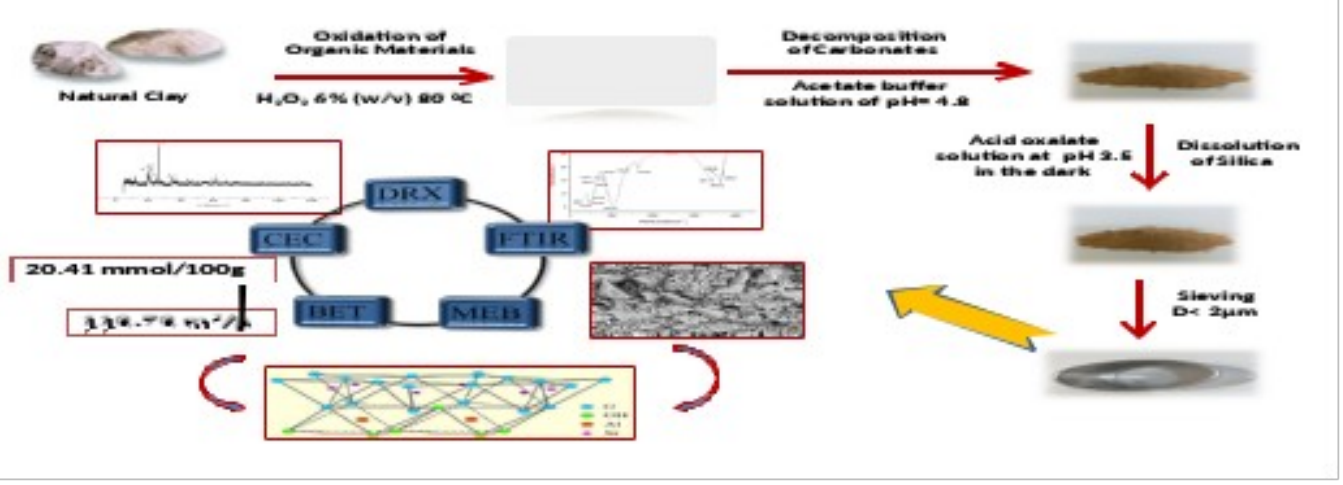

A b stract

Keywords:

BET

clay minerals

El-Oued

FT-IR

SEM

XRD
The main purpose of the present study is the identification of the physico-chemical characteristics of local clay from a southeast province of Algeria (El Oued).A preliminary purification of organic compounds and calcite has been done in order to obtain granules with a diameter less than $2 \mu \mathrm{m}$. Obtained granules were characterized by X-ray diffraction, FTIR, BET, SEM/EDS and CEC. X-ray diffraction shows a majority composition of illite, moderately of kaolinite and minority of quartz. FTIR showed the presence of all the characteristics peaks of the studied clay. The BET method reveals a specific area of about $110.786 \mathrm{~m}^{2}$./g.SEM shows irregular shapes with ragged edges. EDS confirmed the results obtained by XRD. The value of CEC is about $20.416 \mathrm{mmol} / 100 \mathrm{~g}$. 
Clay refers to anaturally occurring material composed primarily of fine-grained minerals. The minerals found in clay are generally silicates less than 2 microns in size [1].Clay is used as a rock term and as a particle-size term in the mechanical analysis of sedimentary rocks, soils, etc. As a rock term, it is difficult to define precisely, because of the wide variety of materials that have been called [2].

The first identification of a surface clay mineral is that it has a small grain size, generally $<2 \mu \mathrm{m}$. Even if the reasons for the small crystal size, which are constantly observed are not fully understood at present, it is certainly the major characteristic of surface clay minerals [3].

However, the rapid change of mineralogy, on a geological scale at least, indicates subtle changes in the mineral structure as determined by X-ray diffraction, the major identification tool for clay minerals. Such change is the result of different chemical equilibrium [4].

The mineralogical and physic-chemical properties of clays are of particular interest in many applications such as water treatment, paint, the barrier for pollutants, adsorbent, catalyst, etc [5-7].

*Corresponding author.

E-mail address: zobeidi.aa@gmail.com(AmmarZobeidi).

The interest given in recent years to the study of clays by numerous laboratories throu- ghout the world is justified by their abundance in nature, their low cost, and the presence of electrical charges on their surfaces and, above all, the exchangeability of the interfoliarcations. All these properties make the clay a material of exceptional quality [8]. Several previous works worldwide has shown that clay minerals of smectite, montmorillonite, bentonite, illite, vermiculite, kaolinite or sepiolite have heavy metal adsorption capacities in effluents and waters contaminated.

Giving identification to new clay requires its characterization by several physicochemical methods (FTIR, XRD, SEM, BET, and CEC) to evaluate the potential of the studied clay to a very specific application (water treatment, etc.).

\section{Materials and methods}

\subsection{Sampling region}

The studied clay was harvested from “SidiOmrane $33^{\circ} 27^{\prime} 20^{\prime \prime} \mathrm{N} 7^{\circ} 11^{\prime} 0^{\prime \prime E}$ ", acommune located $137 \mathrm{~km}$ west of the capital of "El Oued" province and $210 \mathrm{~km}$ east of the capital of "Ouargla" province. The region of sampling is represented in Fig. 1 by a red circle.

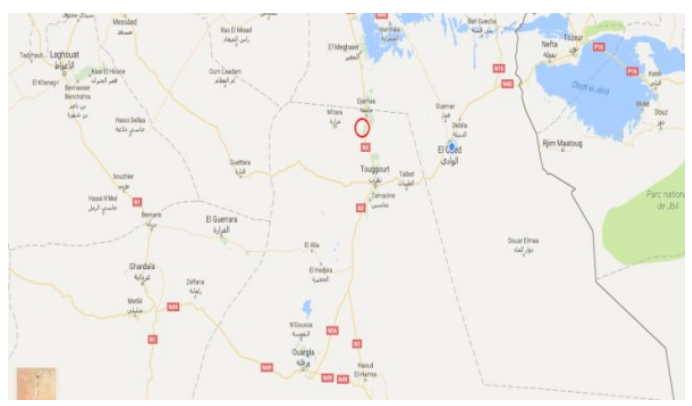

\subsection{Preparation of a Sample of clay}

Hydrogen peroxide $\left(\mathrm{H}_{2} \mathrm{O}_{2} \quad 6 \%\right.$ w/v) was purchased from Kompass. Hydrochloric acid and sodium hexametaphosphate were purchased from Sigma Aldrich. The raw clay was preliminarily subjected to pre-sieving by a cascade of sieves in order to obtain sizes of less than 5 microns. Then it was gently crushed into powder and then treated with hydrogen peroxide $(6 \% \mathrm{w} / \mathrm{v})$ to remove organic compounds. A $2 \mathrm{M}$ hydrochloric acid solution was added then washed with distilled water several times to remove chloride and finally was dried at $105^{\circ} \mathrm{C}$. Pipette method with the addition of a dispersible component (sodium hexa-metaphosphate) was used to obtain granules less than 2 microns. In order to confirm that all the granules size, a 2-micronelectrospun sieve was used. The obtained granules were washed several times with bi-distilled water and by using the centrifuge to completely remove the chloride. The obtained powder was dried at $105{ }^{\circ} \mathrm{C}$ [9].

\subsection{X-ray fluorescence}

X-ray diffraction (XRD) analysis was performed using automated (PAN analytical X'Pert-Pro) diffractometer equipment with CuK $\alpha 1$ radiation source with1.540598 $\AA$ of wavelength, at a step size angle of $0.02^{\circ}$, and a scan range from 5.053 o to 120.046 ․

\subsection{Fourier-transform infrared spectroscopy}

The study was carried out on a compacted clay pellet at a pressure of $80 \mathrm{kPa}$ using a Shimadzu type IR AFFINITY-1 apparatus with a scan number equal to 8 .

\subsection{Brunauer-Emmett-Teller method (BET)}

A sample of $0.2026 \mathrm{~g}$ was degassed at $100^{\circ} \mathrm{C}$ for 12 hours. The analysis was done with a Micromeritics ASAP 2020 V4.03 device with 77K liquid nitrogen.

\subsection{Scanning Electron Microscope/EDS}

Morphological, quantitative and qualitative analyses of the clay sample were carried out using SEM model JEOL 840.

\subsection{Cation-exchange capacity (CEC)}

The cation exchange capacity of the clay was determined by the Met son method [10]. The latter uses a clay mass $\mathrm{m}=$ $10 \mathrm{~g}$. The mass was coated with an ammonium acetate solution of $1 \mathrm{~mol} / \mathrm{L}$ and then washed with isopropanol by filtration under vacuum and then finally washed with potassium chloride $1 \mathrm{~mol} / \mathrm{L}$ solution to replace ammonium ions with potassium ions. The concentration of ammonium in the spray was measured using the chromatic method. The calculated concentration was about $\mathrm{C}=147 \mathrm{mg} / \mathrm{L}$.

CEC was calculated according to the following relationship:

$$
C E C(m E q / 100 g)=\frac{C * V * 100}{18 * m} \ldots .
$$

Where:

C: ammonium concentration ( $\mathrm{mg} / \mathrm{L})$;

$\mathrm{V}$ : ammonium volume (L);

$\mathrm{m}$ : clay mass (g). 


\section{Results and discussion}

\subsection{XRD analysis}

The diffraction pattern from XRD is shown in Fig 2.From the obtained figure it is observed that illiteis the common major phase in the studied sample however, kaolinite and quartz are also present in minor quantity. To dissect the spectrum of DRX, software containing a large database called Match!V.2 was used. Table 1 summarizes the most intense peaks obtained by this software. The relatively high intensity of the quartz peaks in the WC clay (Fig 2) indicates a significant presence of the free silica.

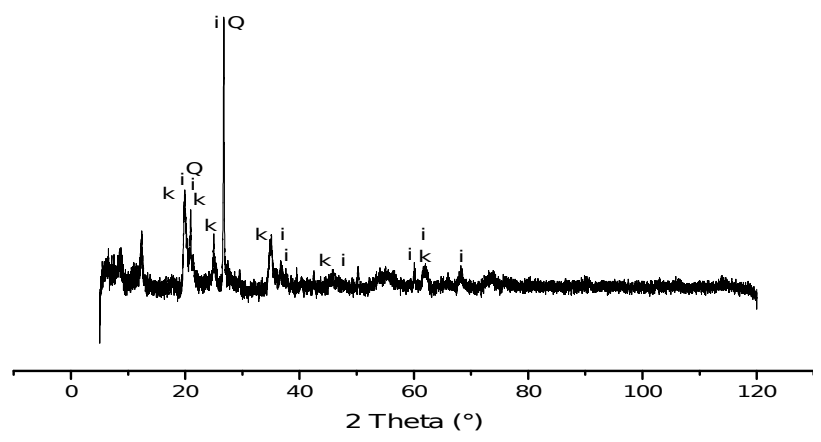

Fig. 2. X-ray diffraction FT-IR of studied clay.

\subsection{Infrared Spectroscopy (FTIR) characterization}

Infrared spectroscopy was used to complete the analysis of the clay sample and to reconfirm the results that were showed in Xray Diffraction. The spectra obtained are illustrated in Fig 3 . The $\mathrm{OH}$ stretching vibration bands at $3622.32 \mathrm{~cm}^{-1}, 3695.61 \mathrm{~cm}^{-1}$, $1635.64 \mathrm{~cm}^{-1}, 798.53 \mathrm{~cm}^{-1}$ indicate the presence of kaolinite. Nevertheless, at $3421.72 \mathrm{~cm}^{-1}$ indicates the presence of water. However, $\mathrm{OH}$ stretching vibration band at $3552.88 \mathrm{~cm}^{-1}$ indicates internal $\mathrm{OH}$. The Si-O-Al stretching vibration bands at $428.2 \mathrm{~cm}^{-1}, 474.49 \mathrm{~cm}^{-1}, 752.24 \mathrm{~cm}^{-1}, 1033.85 \mathrm{~cm}^{-1}$ show the presence of illite, while at $694.37 \mathrm{~cm}^{-1}$ is an evidence of the presence of kaolinite. The $\mathrm{Si}-\mathrm{O}-\mathrm{Si}$ stretching vibration bands at $532.35 \mathrm{~cm}^{-1}$ and $779.24 \mathrm{~cm}^{-1}$ indicate the presence of quartz. The Al-O band at $1392.61 \mathrm{~cm}^{-1}$ and the $\mathrm{Al}-\mathrm{OH}$ stretching vibration band at $914.24 \mathrm{~cm}^{-1}$ are also marks of the presence of illite. Table 2 resumes the principal peaks. It should be noted that a small, insignificant peak appears at about $2380.16 \mathrm{~cm}^{-1}$ indicating the presence of a carbon from carbonate component in the sample.

Table1:

Qualitative analysis of the X-ray diffraction results of the studied clay sample

\begin{tabular}{ccccc}
\hline $2 \theta\left({ }^{\circ}\right)$ & $\begin{array}{c}\text { d-spacing } \\
(\AA)\end{array}$ & Intensities & Phase & Reference \\
\hline 19.73 & 4.4952 & 271.69 & & \\
19.92 & 4.4500 & 383.58 & Illite & {$[11]$} \\
20.68 & 4.2924 & 168.27 & & \\
26.62 & 3.3463 & 430.52 & & \\
19.85 & 4.4600 & 361.32 & & \\
20.34 & 4.3633 & 206.28 & & \\
20.45 & 4.3400 & 163.61 & Kaolinite & \\
24.86 & 3.5784 & 147.87 & & {$[13]$} \\
34.97 & 2.5638 & 185.91 & & \\
35.09 & 2.5551 & 181.03 & & \\
20.9 & 4.2469 & 283.54 & Quartz & \\
26.69 & 3.3301 & 471.32 & & \\
\hline
\end{tabular}

FTIR bands of the natural clay

\begin{tabular}{cccc}
\hline $\begin{array}{c}\text { Absorptio }\left(\mathrm{cm}^{-}\right. \\
\left.{ }^{1}\right)\end{array}$ & Molecular bond & Phase & Reference \\
428.20 & Si-O-Al stretching & illite & {$[14]$} \\
474.49 & Si-O-Al stretching & illite & {$[15]$} \\
532.35 & Si-Ostr. Si-O-Al str & Quartz /kaolinite & {$[14]$} \\
694.37 & Si-O- stretching & kaolinite & {$[14]$} \\
752.24 & illite & {$[16]$} \\
779.24 & Si-O-Al vibration & quartz & {$[16]$} \\
798.53 & Si-O & kaolinite & {$[17]$} \\
914.26 & OH stretching & illite & {$[18]$} \\
1033.85 & Al-OH bending & Illite/kaolinite & {$[19]$} \\
1392.61 & illite & {$[16]$} \\
1635.64 & Al-O out-of-plane & kaolinite & {$[17]$} \\
2380.16 & OH stretching & carbonate & {$[20]$} \\
3421.72 & C=O & water & {$[12]$} \\
3552.88 & $\mathrm{OH}$ stretching & wh & {$[15]$} \\
3622.32 & $\mathrm{OH}$ stretching & OH interne & {$[16]$} \\
3695.61 & $\mathrm{OH}$ stretching & kaolinite & {$[16]$} \\
\hline
\end{tabular}

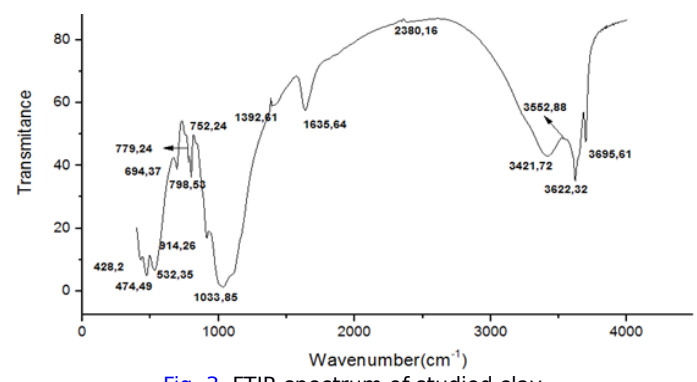

Fig. 3. FTIR spectrum of studied clay.

\subsection{BET Surface Area and BJH Pore Size/Volume}

$B E T$ is an extension of the Langmuir treatment for multi-layer adsorption on a flat and homogeneous surface, and it is important that solid-gas systems are related to condensation [21].

From the curve shape shown in Fig. 4 it can be verified that the isotherm is of type IV however, Fig. 5 showed that the studied clay is mainly a medium pore material. The BET surface area is $110.7064 \mathrm{~m}^{2} / \mathrm{g}$. It is accepted that the desorption isotherm is more appropriate than the adsorption isotherm for determining the pore size distribution of an adsorbent.

The surface characteristics of the studied material are given in Table 3,and the pore size is $76.712 \AA$ and the pore volume is $0.152186 \mathrm{cc} / \mathrm{g}$, this value is taken from the cumulative desorption of $\mathrm{BJH}$ from Table 3. The distribution of the pore size of the clay studied in Figure 5 shows that the whole studied clays are of the mesoporoustype and that the average size of nanoparticles is $541.974 \AA$.

Table 3:

Surface properties of the natural clay

\begin{tabular}{cccc}
\hline Parameter & $\begin{array}{c}\text { Surface } \\
\text { area } \\
\left(\mathrm{m}^{2} / \mathrm{g}\right)\end{array}$ & $\begin{array}{c}\text { Pore } \\
\text { volume } \\
(\mathrm{cc} / \mathrm{g})\end{array}$ & $\begin{array}{c}\text { Pore } \\
\text { size } \\
(\AA)\end{array}$ \\
\hline $\begin{array}{c}110.7064 \\
\text { BET Surface Area }\end{array}$ & $/$ & $/$ \\
$\begin{array}{c}\text { BjH cumulative } \\
\text { adsorption }\end{array}$ & 170.2894 & $/$ & $/$ \\
$\begin{array}{c}\text { BJH cumulative } \\
\text { desorption }\end{array}$ & 72.061 & 0.150018 & 83.273 \\
\hline
\end{tabular}




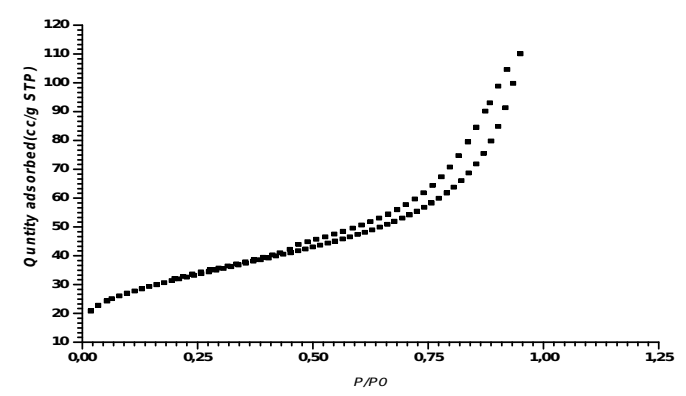

g. 4. Nitrogen adsorption isotherm for El-Oued Clay

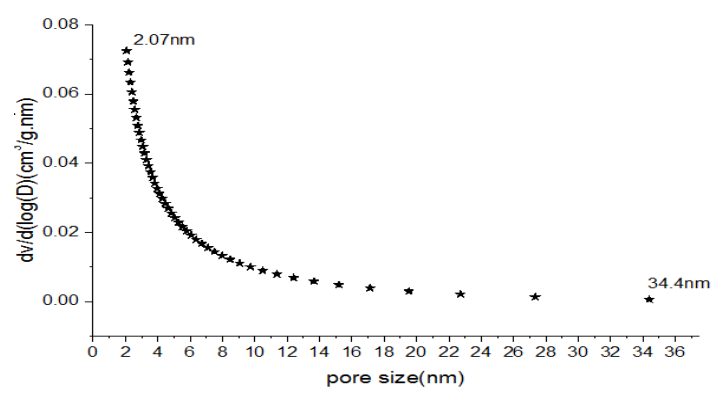

Fig. 5. Pore size distribution of El-Oued Clay

\subsection{SEM/EDS characterization}

The Fig. 6 shows clusters of different sizes and dimensions with rough and irregular edges. The clusters vary in size at a scale of fewer than 2 microns. Table 4 and Fig. 7 show the EDS analysis of elemental chemical composition. The analysis shows the actual percentages of the various elements contained in the clay. The table shows percentages of $52.4,15.3$ and $8.9 \%$ respectively of $\mathrm{O}$, Siand $\mathrm{Al}$ respectively. The lowest amounts are of $\mathrm{Na}$ and $\mathrm{P}$. The EDS analysis revealed very reasonable similarities in results with XRD.

The image also shows particles with small dimensions smaller than a micrometer and predominant in the image. Small-sized kaolinite platelets less than $2 \mu \mathrm{m}$ associated with large particles i.e. large than $10 \mu \mathrm{m}$ appear. Moreover, the sample contains some of theorganic compounds that we discover through the dark areas shown in the picture. The kaolinite may be poorly crystalline due to the presence of impurities. Several authors have found that impurity elements and also illite decrease the whiteness of kaolinites [22-25].

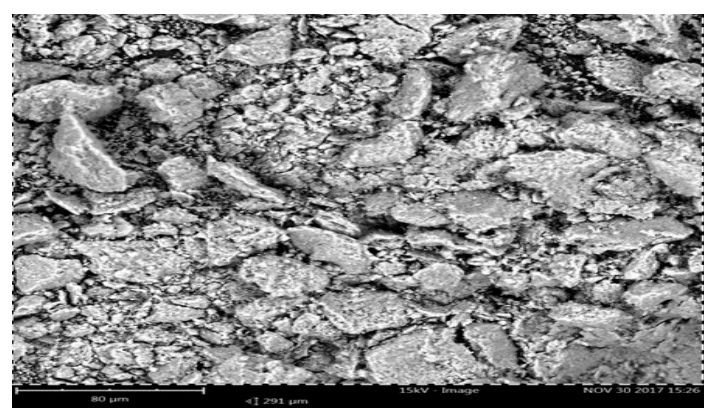

Fig. 6. SEM image of local clay

Table 4.

EDS analysis of elemental chemical composition

\begin{tabular}{ccc}
\hline $\begin{array}{c}\text { Element } \\
\text { Symbol }\end{array}$ & $\begin{array}{c}\text { Weight } \\
\text { Concentration(\% }\end{array}$ & Error \\
& ) & \\
\hline $\mathrm{Si}$ & 15.3 & 0.2 \\
$\mathrm{O}$ & 52.4 & 0.2 \\
$\mathrm{Al}$ & 8.9 & 0.1 \\
$\mathrm{Fe}$ & 5.9 & 0.3 \\
$\mathrm{Mg}$ & 1.8 & 0.7 \\
$\mathrm{~K}$ & 1.6 & 0.3 \\
$\mathrm{Ca}$ & 1.2 & 1.0 \\
$\mathrm{~N}$ & 6.4 & 1.2 \\
$\mathrm{P}$ & 0.6 & 1.7 \\
$\mathrm{Na}$ & 0.9 & 0.9 \\
$\mathrm{C}$ & 4.9 & 0.4 \\
\hline
\end{tabular}

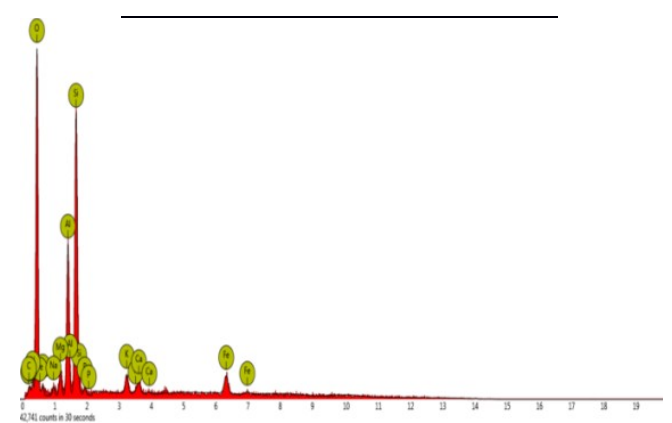

Fig. 7. EDS Spectrum pattern of studied clay

\subsection{Cation exchange capacity(CEC)}

The experimental protocol and the equation that allows the calculation of CEC have been described previously in section 2.7. Calculated CEC is $20.416 \mathrm{mmol} / 100 \mathrm{~g}$.

\section{Conclusion}

This work is aimed to determine the mineral properties of natural clay at Saharan zone located southwest of Algeria. Through our study of the purified natural clay, its mineral structure and its physicochemical properties using different analytical methods were determined. It was found that the clay contained mostly the illite with the presence of kaolinite and a minor quantity of quartz using RDX and FTIR as complementary studies. However, BET analysis reveals that the studied clay is mesoporous and it has an isotherm type IV. While its surface area is $110.7064 \mathrm{~m}^{2} / \mathrm{g}$ and its pore size and pore volumes are $0.152186 \mathrm{~cm}^{3} / \mathrm{g}$ and $76.712 \AA$ respectively, the average particle size is $541.974 \AA$.

\section{Declaration of Competing Interest}

The authors declare that they have no known competing financial interests or personal relationships that could have appeared to influence the work reported in this paper.

\section{Acknowledgments}

We thank the anonymous reviewers for their careful reading of our study and their many constructive comments and suggestions 


\section{Funding}

The author(s) received no financial support for the research, authorship, and/or publication of this article.

\section{References}

[1] K.Fukushi, H.Sakai, T.Itono, ,A.Tamura, S. Arai (2014) Desorption of Intrinsic Cesium from Smectite: Inhibitive Effects of Clay Particle Organization on Cesium Desorption. Environmental Sciencel Technology,48, 10743-10749.

[2]M.Markov, V.Levine, A.Mousatov, E. Kazatchenko (2005) Elastic properties of double-porosity rocks using the differential effective medium model, Geophysical Prospecting, 53, 733-754.

[3] M.Erdemoğlu, S.Erdemoğlu, F.Sayılkan, M. Akarsud, S. Sener, H.Sayılkan (2004) Organo-functional modified pyrophyllite: preparation, characterisation and $\mathrm{Pb}(\mathrm{II})$ ion adsorption property. Applied Clay Science, 27, 41-52.

[4]B.B.Velde, A. Meunier (2008) Part of the solution to environmental degradation-the book aids our understanding of mineral formation, The Origin of Clay Minerals in Soils and Weathered Rocks, first edition, Springer, Amsterdam.

[5]L.Sun, C. G.Tian, M.T.Li, X. Y.Meng, L.Wang, R. H.Wang, J. Yin,H.G. Fu (2013) From coconut shell to porous graphene-like nanosheets for high-power supercapacitors, Journal of Materials Chemistry A, 1, 6462- 6470.

[6]A.B.Morgan and J.W.Gilman (2003) Characterization of polymer-layered silicate (clay) nanocomposites by transmission electron microscopy and X-ray diffraction: A comp- arative study, Journal of Applied Polymer Science, 87, 1329-38

[7]F.Bergaya, B.K.G.Theng,G.Lagaly (2006) General introduction: clays, clay minerals, and clay science, Handbook of Clay Science, First Edition. Elsevier,1,1-18.

[8]Y.L. Liu, H.W. Walker, J.J. Lenhart (2019) Adsorption of microcystin-LR onto kaolinite,

illite and montmorillonite, Chemosphere, 220, 696-705.

[9]G. Dirk (2007) Techniques to measure grain-size distributions of loamy sediments: a comparative study of ten instruments for wet analysis, Sedimentology,55, 65-96.

[10]F.Rees, M. O.Simonnot, J. L. Morel (2013) Short-term effects of biochar on soil heavy metal mobility are controlled by intra-particle diffusion and soil $\mathrm{pH}$ increase, European Journal of Soil Science, 65, 149-161.

[11]A. F. Gualtieri (2000) Accuracy of XRPD QPA using the combined Rietveld-RIR method, Journal of Applied Crystallography, 33, 267-278.

[12]M.Jana, K. Peter (2001) Baseline Studies of the Clay Minerals Society Source Clays: Infrared Methods, Clays and Clay Minerals, 49, 410-432.

[13]R. M.Hazen, L.W.Finger, R. J.Hemley, H. K.Mao (1989) High-pressure crystal chemistry and amorphization of $\alpha$-quartz Solid State Communications, 72, 507-511.

[14]A. H.Dewan, S.Mustafi, M.Ahsan, M. S. Ullah (2014) Investigation on physical properties of patia clay (Chittagong), Bangladesh, Bangladesh, Journal of scientific and industrial research, 49, 255-262.

[15]Yen-Ling Liu, Harold W. Walker, John J. Lenhart (2019) The effect of natural organic matter on the adsorption of microcystin-LR onto clay minerals, Colloid Surf. A-Physicochem. Eng. Asp , 583,123964.

[16] S.N.reeti, B. K.Singh (2007) Instrumental characterization of clay by XRF, XRD and FTIR, Bulletin of Materials Science, $30,235-238$

[17]Achyut K. Pandaa,b, B.G. Mishraa, D.K. Mishrac, R.K. Singha (2010) Effect of sulphuric acid treatment on the physico-chemical characteristics of kaolin clay, Colloid Surf. A-Physicochem. Eng. Asp, 363(1),98-104.

[18]D. Atia, A A.Bebba, L. Haddad, A. Zobeidi (2018) Elimination of organic pollutants from urban wastewater by illite-kaolinite local clay from south-east of Algeria, Ciência e TécnicaVitivinícola, 33(7), 17-28

[19]S.Kang, B. Xing (2007) Adsorption of Dicarboxylic Acids by Clay Minerals as Examined by in Situ ATR-FTIR and ex Situ DRIFT, Langmuir, 23, 7024-7031. [20]B.Suna, , G. Elif (2009) Pore structure and surface acidity evaluation of Fe-PILCs, Turkish Journal of Chemistry,33, 843-856.

[21]M. Terashima, M. Fukushima, S. Tanaka (2004) Influence of pH on the surface activity

humic acid: micelle-like aggregate formation and interfacial adsorption, Colloid Surf. A-Physicochem.Eng. Asp. 247 (1-3), 77-83.

[22]S. Chandrasekhar, S. Ramaswamy (2002) Influence of mineral impurities on the properties of kaolin and its thermally treated products, Applied Clay Science,21,133142.

[23]P. A. Schroeder, N. D. Melear, R. J. Pruett (2003) Quantitative Analysis of Anatase in Georgia Kaolin Using Raman Spectroscopy. Applied Clay Science, 23(5-6), pp.299-308.
[24]R. Divacaran, V. N. Sivasankara Pillai ( 2004) Mechanism of Kaolinite andTitanium Dioxide Flocculation Using Chitosan-Assistance by Fulvic Acids?, Water Research, 38(8), pp.2135-2143.

[25]P. Raghavan, S. Chandrasekhar, V. Vogt, E. Gock (2004) Separation of titanoferrous impurities from kaolin by high shear pretreatment and froth flotation,

Applied Clay Science, 25(1-2), pp.111-120. 